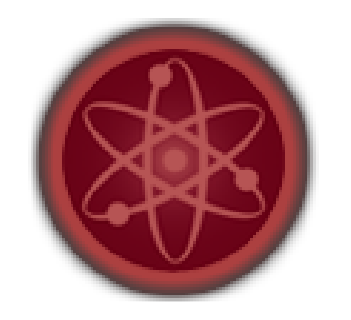

JUURNALRU

Мызров М.В.

Саратовский соичально-экономический институт РЭУ

им. Г.В. Плеханова

Саратов, Россия

doi: 10.18411/1j2016-2-16

\title{
Роль информационных технологий как источника информации в современном мире
}

\section{Введение}

Информационное обеспечение играет большую роль в различных сферах деятельности. Благодаря информационному обеспечению увеличивается производительность, повышается качество продукции, более эффективно используются ресурсы, появляются новые сферы деятельности и т.д.

\section{Поддержка государством информационных технологий}

Поддержка и финансирование программ развития информационных технологий находится в центре внимания всех развитых государств. В качестве механизмов поддержки государство использует систему грантов, конкурсов, целевых программ развития, направленных на разработку новых идей в сфере информационного обеспечения. Кроме этого, государство стремится обеспечить доступ исследователей и разработчиков к современным информационным ресурсам. Одна из целей, которую преследует государство поддержкой данных мероприятий, является конвертация знаний в рыночный продукт, способный выйти на мировой рынок.

В качестве особенностей применения современных информационных технологий в мире, можно привести следующие: 
1. Электронные информационные ресурсы в развитых странах становятся одним из основных источников информации;

2. Все больше научных материалов переводится в электронный формат. В связи с этим, кризис практически не сказался на производителях электронных ресурсов;

3. Все больше исследователей и общественных деятелей публикуются либо в бесплатных журналах, либо выкладывают свои труды в открытый доступ, например, на электронном pecypce: http://link.springer.com/;

4. Во многих странах подвергается критике стремление научных и общественных изданий на получении прибыли от распространения информации;

5. Создание и использование электронных ресурсов не только в развитых, но и в развивающихся странах происходит ускоренными темпами.

\section{Информационные ресурсы в сфере образования}

На данный момент в виде электронных ресурсов накоплен огромный массив информации, но проблемой остается организация доступа к этим ресурсам и поиск нужной информации. Особое место эта проблема занимает в сфере образования, где свободный и быстрый доступ к образовательным ресурсам имеет повышенный приоритет. Поэтому развитие и применение информационно-коммуникационных технологий (ИКТ) в сфере образования является актуальной задачей.

Основными условиями развития ИКТ в сфере образования являются:

1. Обеспечение материальной базы (технические средства и программное обеспечение);

2. наличие ИКТ-компетентных участников образовательного процесса;

3. создание информационного образовательного пространства (электронной образовательной среды) на основе действующей информационной среды образовательного учреждения;

В настоящее время в образовании все чаще за основу берется 
компетентностный подход. Ключевые компетентности современного человека формулируются Комиссией Евросоюза в следующем виде:

1. коммуникация на родном языке;

2. коммуникация на иностранном языке;

3. математическая компетентность и базовая естественнонаучная и технологическая компетентность;

4. цифровая (ИКТ) компетентность;

5. умение учиться;

6. социальная и гражданская компетентность;

7. инициативность и предприимчивость;

8. культура и способность к самовыражению;

Для решения указанных задач в сфере образования создается достаточно большое количество программ, направленных на улучшение качества обучения или в помощь обучающимся. Создание данных программ может спонсироваться государством, однако большинство программ принадлежит частным владельцам и является коммерческим продуктом. При этом многие задачи, стоящие перед системой образования, все еще не имеют эффективных программных средств для своего решения. Например, задачи построения и оптимизации бизнес процессов в сфере образования, задачи обнаружения и структуризации новых знаний (data mining) и др., не всегда находят ответ в программных средствах.

Подводя итоги можно утверждать, что информационные технологии стали неотъемлемой частью практически любой сферы деятельности. От информационного обеспечения зависит успешная деятельность самых разных организаций. Многие учебные заведения все активнее применяют различные информационные ресурсы в образовании, но не все направления обучения поддерживаются программным обеспечением. Часто преподавателям так же не хватает программного продукта, который отвечал их запросам. В связи с этим для разработчиков программных средств есть множество ниш в сфере образования, которые они могут занять. 


\section{Литература:}

1. Проект распоряжения Правительства РФ об утверждении комплекса мероприятий, направленных на увеличение к 2015 году доли публикаций российских исследователей в общем количестве публикаций в мировых научных журналах, индексируемых в базе данных «Сеть науки» (Web of Science) [Электронный ресурс]. - www.минобрнауки.рф/документы/3119.

2. Конкурсы Федеральной целевой программы «Исследования и разработки по приоритетным направлениям развития научно-технологического комплекса России на 2014-2020 годы» [Электронный ресурс]. www.2014.fcpir.ru/participation_in_program/contests/list_of_contests/receipt_of _applications/2014-14-596-0002.

3. Hormia-Poutanen K., Xenidou-Dervou C., Kupryte R., Stange K., Kuznetsov A., Woodward H. Consortia in Europe: Describing the Varios Solutions through Four Country Examples // Library Trends. 2006. Vol. 54. No. 3. P. 359-381.

4. Kuznetsov Alexander, Razumova Irina. Selling to the BRIC: Russia // Learned Publishing. 2011. Vol. 24. No. 2. P. 139-144.

5. Гусятников В.Н., Безруков А.И., Соколова Т.Н. Инструменты интеграции систем управления качеством в образовательный процесс // Интеграция образования. 2010. № 4. С. 16-19. 